\title{
Urinary incontinence nursing diagnoses in patients with stroke*
}

\author{
Diagnósticos de enfermagem de incontinência urinária em \\ pacientes com acidente vascular cerebral \\ Diagnósticos de enfermería de incontinencia urinaria en \\ pacientes con accidente vascular cerebral
}

Telma Alteniza Leandro", Thelma Leite de Araujo², Tahissa Frota Cavalcante ${ }^{3}$, Marcos Venícios de Oliveira Lopes², Tyane Mayara Ferreira de Oliveira ${ }^{4}$, Ana Cecília Menezes Lopes ${ }^{4}$

\footnotetext{
* Extracted from the dissertation "Prevalência de diagnósticos de enfermagem de incontinência urinária em pacientes com acidente vascular cerebral," Universidade Federal do Ceará, 2014

${ }^{1}$ Universidade Federal do Ceará, Programa de Pós-Graduação em Enfermagem, Fortaleza, CE, Brazil.

${ }^{2}$ Universidade Federal do Ceará, Departamento de Enfermagem, Fortaleza, CE, Brazil.

${ }^{3}$ Universidade da Integração Internacional da Lusofonia Afro-Brasileira, Redenção, CE, Brazil

${ }^{4}$ Universidade Federal do Ceará, Curso de Graduação em Enfermagem, Fortaleza, CE, Brazil.
}

\section{ABSTRACT}

Objective: Identifying the prevalence of Stress urinary incontinence (SUI), Urge urinary incontinence (UUI), Functional urinary incontinence (FUI), Overflow urinary incontinence (OUI) and Reflex urinary incontinence (RUI) nursing diagnoses and their defining characteristics in stroke patients. Method: A cross-sectional study with 156 patients treated in a neurological clinic. Data were collected through interviews and forwarded to nurses for diagnostic inference. Results: $92.3 \%$ of the patients had at least one of the studied diagnoses; OUI showed the highest prevalence $(72.4 \%)$, followed by FUI (53.2\%), RUI (50.0\%), UUI (41.0\%) and SUI (37.8\%). Overdistended bladder and reports of inability to reach the toilet in time to avoid urine loss were the most prevalent defining characteristics. A statistically significant association of the defining characteristics with the studied diagnosis was verified. Conclusion: The five incontinence diagnoses were identified in the evaluated patients, with different prevalence.

\section{DESCRIPTORS}

Nursing Diagnosis; Urinary Incontinence; Stroke.
Corresponding author:

Telma Alteniza Leandro

Av. João Pessoa, 3912, Apto 08 - Bairro Damas

CEP 60425-812 - Fortaleza, CE, Brazil

telmaleandro21@yahoo.com.br
Received: 03/17/2015

Approved: 09/23/2015 


\section{INTRODUCTION}

Urinary incontinence Nursing Diagnoses are included in NANDA International, Inc. (NANDA-I) in Domain 3: Elimination and Exchange, Class 1: Urinary Function ${ }^{(1)}$. In this class, nine nursing diagnoses related to urinary elimination are present. Five of these are presented as the real diagnosis for incontinence, which are: Stress urinary incontinence (00017), Urge urinary incontinence (00019), Functional urinary incontinence (00020), Overflow urinary incontinence (00176) and Reflex urinary incontinence (00018) $)^{(1)}$.

Urinary incontinence is an issue relatively little investigated by health professionals and studies on the prevalence of nursing diagnoses on this topic are scarce ${ }^{(2)}$. For the International Continence Society, urinary incontinence is defined as any involuntary loss of urine ${ }^{(3)}$. However, the clinical situation in Nursing may present different nursing diagnoses.

As it is known to trigger important changes that affect the quality of life of individuals, urinary incontinence condition has been considered a public health problem. The distress brought forth by incontinence generates impact on physical, psychological and social aspects of the subjects ${ }^{(4)}$. This situation has led professionals from different areas of health, medicine, physical therapy, and nursing, among others, to focus on studying the theme in different clinical situations.

Among the situations that imply the clinical condition of urinary incontinence are neurological disorders, and among them, the observation of incontinence among stroke patients ${ }^{(5)}$. Regardless of the cause, stroke can alter brain structures responsible for controlling urination, thus compromising the urinary system ${ }^{(6)}$.

A study realized in a city in China with 711 patients after stroke identified prevalence of $44.3 \%$ of urinary incontinence, and the main risk factors for incontinence associated with stroke were the stroke, parietal lobe lesion, chronic cough, aphasia and post-stroke depression ${ }^{(5)}$. A study on patients after ischemic stroke showed a 79\% prevalence of urinary incontinence ${ }^{(6)}$.

Various types of urinary incontinence have different etiology and pathophysiology, and understanding them is essential for treatment and a promising prognosis ${ }^{(7)}$. Similarly, nurses may have difficulty in inferring the different nursing diagnoses of urinary incontinence, since some defining characteristics can be present in more than one diagnosis, while others have similarities with one another. These similarities could compromise the diagnostic reasoning, since nurses do not always recognize the differences between the names/terms of the characteristics, which can be accentuated by the lack of conceptual and/or operational definitions of NANDA-I characteristics ${ }^{(1)}$.

The fact that some of these human responses are difficult to assess due to the complexity of measurement is also worth noting. The construction of protocols with conceptual and operational definitions for each defining characteristic is recommended to allow a more accurate diagnostic reasoning process. Conceptual and operational definitions, as well as standardized data collection help in differentiating similar characteristics.
The need to care for people with stroke has led to the development of different studies, which are intended to identify different nursing diagnoses that may constitute the focus for care planning. Among them we can mention studies related to mobility issues/locomotion ${ }^{(8)}$, investigating swallowing problems/risk of aspiration ${ }^{(9)}$, and risk of falls ${ }^{(10)}$, however, urinary incontinence problems have not yet had the same attention, although they represent a frequent condition observed empirically in clinical testing.

Thus, research on diagnostic prevalence of urinary incontinence are needed in stroke patients, because by eliciting responses from this population, nurses will be able to implement more dedicated nursing care to improve the elimination standard for these patients, thus targeting more specific interventions and with better quality.

This study has the following objectives for contributing to the knowledge in the area: determining the prevalence of Stress urinary incontinence (SUI), Urge urinary incontinence (UUI), Functional urinary incontinence (FUI), Overflow urinary incontinence (OUI) and Reflex urinary incontinence (RUI) nursing diagnoses and their defining characteristics in stroke patients; To determine the prevalence of the defining characteristics of these diagnoses; To verify the association of diagnoses with one another and with the defining characteristics.

We hope that the knowledge produced in this study may expand the theoretical basis used by nurses in determining nursing diagnoses of urinary incontinence through investigating their defining characteristics.

\section{METHOD}

A cross-sectional study conducted in a neurology clinic of a tertiary public hospital, located in the city of Fortaleza/ Ceará, northeastern Brazil, in the period of September to November 2013.

The study population was composed of 156 patients with a CVA diagnosis, selected by convenience, in a consecutive manner. The parameters for calculating the sample were: confidence level of $95 \%(Z \alpha)$, sampling error of $7 \%$, and the prevalence was based on a study ${ }^{(11)}$ that had a value of $27 \%$ for the nursing diagnosis of Stress urinary incontinence. This nursing diagnosis was adopted for calculation because it was the only one that had been investigated with an estimated prevalence in a previous study. It is important to emphasize that this prevalence study was not conducted with people with CVA, and has been adopted due to the absence of others with the population under consideration.

Inclusion criteria were: being registered and attended the neurology clinic due to a stroke, regardless of the type; being able to respond to interview questions; being 18 years or older.

Exclusion criteria were: patients with cystostomy and nephrostomy; with bladder probes and continuous use of diapers; history of prostate cancer, hypoplasia and prostatic hyperplasia, partial and full prostatectomy surgery; surgical history of perineoplasty. The study excluded patients who could display urinary incontinence due to other causes than stroke.

The instrument used for data collection was based on defining characteristics of urinary incontinence nursing di- 
agnoses of NANDA- $\mathrm{I}^{(1)}$. Two nurses with clinical experience and expertise in nephrology analyzed the instrument to ascertain the adequacy and relevance of the designed content. Those skilled nurses suggested the inclusion of a question to investigate involuntary loss of urine before the stroke (heeded suggestion) and questions relating to kidney problems of the nephrological order that were not taken into consideration since they were not focus of the study.

There was some space allocated in the instrument to investigate personal information, sociodemographic data, and for entering information that enabled identification of incontinence diagnoses. The defining characteristics proposed by NANDA-I for the nursing diagnoses under study were analyzed, and for the preparation of the sample collection, those that could be identified through patient reporting were adopted.

Thus, the features that rely on external observation were analyzed by investigating defining characteristics from reports, being: Involuntary leakage of small volume of urine with sneezing; Involuntary leakage of small volume of urine with laughing; Involuntary leakage of small volume of urine with coughing; Involuntary leakage of small volume of urine during stress/on exertion; Involuntary leakage of small volume of urine in the absence of detrusor contraction; Involuntary leakage of small volume of urine in the absence of overdistended bladder; Inability to reach toilet in time to avoid urine loss.

In addition, some defining characteristics have been grouped within the same point due to the similarity in their manifestations. The characteristics Reports involuntary loss of urine with bladder contractions and Involuntary loss of urine with bladder spasms have been grouped into a single question. Reports Inability to reach toilet in time to avoid urine loss and Voiding prior to reaching toilet are identical characteristics common to Urgent urinary incontinence diagnostics and Functional urinary incontinence, but the investigation was carried out only once.

The following defining characteristics were not investigated due to the difficulty of measuring them in the study environment: Incomplete emptying of bladder with lesion above pontine micturition center and Incomplete emptying of bladder with lesion above the sacral urination center. Specialized exams that are not routine in the clinic would be necessary to evaluate these defining characteristics.

Data were collected by two nurses, including the researcher, and two previously trained undergraduate Nurs- ing students. The training consisted of eight hours, during which the content related to nursing diagnoses and the urinary system were reviewed, the data collection instrument was presented and thoroughly discussed. To ensure its correct completion, an SOP (standard operating procedure) was drawn up containing the conceptual definitions of each defining characteristic and the operational definitions for correct survey during the interview. For the construction of SOP, a search of the relevant literature and consultation with professionals with experience in urological nursing and nursing diagnoses was necessary. The collection instrument application trial consisted of a four-hour training program.

The data collection instrument was tested with four patients affected by stroke not included in the final sample, as the calibrating the instrument was crucial. The test was performed by nurses and graduate students who participated in the collection. Prior application showed that the items to be investigated were understandable to the study context, therefore, not needing necessary adjustments considering that the instrument was appropriate.

After data collection, data were gathered in a printout containing the information: gender, age, medical diagnosis, records of information collected in the interview and a list of nursing diagnoses under study. The diagnostician was asked to select one of the options: present or absent.

Four previously trained nurses selected for having publications on diagnoses, interventions and nursing outcomes acted as diagnosticians and realized the above mentioned inferences. The training of the diagnosticians included theoretical information about urinary incontinence nursing diagnoses, their defining characteristics, as well as discussion of physiological and psychosocial aspects of the subject. This moment was relevant, since many of these professionals, despite having conducted research on nursing diagnoses, were not familiar with these specified diagnoses.

After the theoretical part of the training, the diagnosticians received 39 fictitious cases to evaluate the quality of their diagnostic inferences, following the authors recommending this method in order for nurses to achieve the same level of ability to infer diagnoses, providing more homogeneous assessments ${ }^{(12)}$. The same authors recommended checking the following parameters: effectiveness, false positive rate, false negative rate and trend ${ }^{(12)}$.

Table 1 shows the performance of the diagnosticians responsible for the assessment after completion of the workshop.

Table 1 - Results of tests performed after training with nursing diagnosticians, for nursing diagnoses of Urinary Incontinence. Fortaleza, CE, Brazil, 2014.

\begin{tabular}{ccccccccc}
\hline \multirow{2}{*}{ ND } & \multicolumn{9}{c}{ Training 1 } & \multicolumn{3}{c}{ Training 2 } \\
\cline { 2 - 8 } Nurse 1 & E & FN & FP & T & E & FN & FP & T \\
SUI & 1 & 0 & 0 & 1 & 1 & 0 & 0 & 1 \\
UUI & 0.8974 & 0 & 0.5 & - & 1 & 0 & 0 & 1 \\
FUI & 0.8974 & 0.0555 & 0.1428 & 2.1413 & 0.9555 & 0.0555 & 0 & 0 \\
OUI & 0.9743 & 0 & 0.0476 & - & 1 & 0 & 0 & 1 \\
RUI & 0.92 & 0.1666 & 0 & 0 & 1 & 0 & 0 \\
\hline
\end{tabular}




\begin{tabular}{|c|c|c|c|c|c|c|c|c|}
\hline \multirow{2}{*}{ ND } & \multicolumn{4}{|c|}{ Training 1} & \multicolumn{4}{|c|}{ Training 2} \\
\hline & $\mathbf{E}$ & FN & FP & $\mathbf{T}$ & E & FN & FP & $\mathbf{T}$ \\
\hline \multicolumn{9}{|c|}{ Nurse 2} \\
\hline SUI & 0.9230 & 0.1666 & 0 & 0 & 1 & 0 & 0 & 1 \\
\hline UUI & 0.9743 & 0 & 0.0555 & - & 1 & 0 & 0 & 1 \\
\hline FUI & 0.8974 & 0.1666 & 0.0476 & 0.3531 & 1 & 0 & 0 & 1 \\
\hline OUI & 0.9743 & 0.0555 & 0 & 0 & 1 & 0 & 0 & 1 \\
\hline RUI & 1 & 0 & 0 & 1 & 1 & 0 & 0 & 1 \\
\hline \multicolumn{9}{|c|}{ Nurse 3} \\
\hline SUI & 1 & 0 & 0 & 1 & 1 & 0 & 0 & 1 \\
\hline UUI & 0.9743 & 0 & 0.0555 & - & 1 & 0 & 0 & 1 \\
\hline FUI & 0.8461 & 0.1666 & 0.1428 & 0.9112 & 0.9743 & 0 & 0.0476 & 0 \\
\hline OUI & 0.8974 & 0 & 0.1904 & - & 1 & 0 & 0 & 1 \\
\hline RUI & 1 & 0 & 0 & 1 & 1 & 0 & 0 & 1 \\
\hline \multicolumn{9}{|c|}{ Nurse 4} \\
\hline SUI & 0.9230 & 0 & 0.1428 & - & 1 & 0 & 0 & 1 \\
\hline UUI & 0.7179 & 0.1428 & 0.4444 & 1.7714 & 1 & 0 & 0 & 1 \\
\hline FUI & 0.9743 & 0 & 0.0476 & - & 1 & 0 & 0 & 1 \\
\hline OUI & 0.8461 & 0 & 0.2857 & - & 1 & 0 & 0 & 1 \\
\hline RUI & 1 & 0 & 0 & 1 & 1 & 0 & 0 & 1 \\
\hline
\end{tabular}

ND: Nursing Diagnosis; E: Effectiveness; FN: false negative rates; FP: false positive rates; T: Trend; SUI: Stress urinary incontinence; UUI: Urge urinary incontinence; FUI: Functional urinary incontinence; OUI: Overflow urinary incontinence; RUI: Reflex urinary incontinence.

As noted above, another training round proved necessary for nurses to reach the minimum profile established in the study. After reviewing the submitted inconsistencies, these professionals underwent a new assessment of attributes, using different cases from those previously applied. The evaluation was performed according to the method used during the previous evaluation. Upon completion of this step, the diagnosticians were eligible to participate in the study.

During the process of diagnostic inference, nurses were divided into pairs and the printout summarizing the interview of each patient was given to each pair, so that of $156 \mathrm{pa}^{-}$ tients, each pair received 78 interview summaries. Inferences were made separately, without communication between the pair. In cases of disagreement, it was requested that the diagnosticians discuss the situation until reaching consensus.

Data were analyzed with the support of the statistical program SPSS version 21.0 for Windows. For descriptive analysis, the absolute and percentage frequencies were considered. To verify the normality, we used the Kolmogorov-
Smirnov test. Chi-square test was applied to make the association between diagnoses and their defining characteristics. The significance level was 0.05 .

The study was approved by the Research Ethics Committee under number 392.531. Signing of an Informed Consent form was requested from all study participants.

\section{RESULTS}

The evaluated patients were aged between 28 and 87 years, with a mean of 62.28 years (standard deviation 14.71 ). Most were men (50.6\%) and lived with a partner (57.1\%). Regarding the number of family members, a median of two individuals was observed. Most subjects came from the interior of the state of Ceará (55.8\%). In terms of occupation, most were retired (63.5\%), with a median personal income of 678 reais, and an average of five years of study.

Table 2 shows the prevalence of urinary incontinence nursing diagnoses and their respective defining characteristics.

Table 2 - Prevalence of urinary incontinence nursing diagnoses and their defining characteristics in stroke patients - Fortaleza, CE, Brazil, 2014.

\begin{tabular}{|c|c|c|c|c|c|c|c|}
\hline Variables & $\mathbf{N}$ & $\%$ & & $\mathbf{N}$ & $\%$ & P* & $\mathbf{P R}^{* *}$ \\
\hline Diagnostics & & & Defining characteristics & & & & \\
\hline \multirow[t]{4}{*}{ Overflow urinary incontinence } & 113 & 72.4 & Bladder distention & 111 & 98.2 & 0.001 & 3.39 \\
\hline & & & Nocturia & 98 & 86.7 & $<0.001$ & 3.76 \\
\hline & & & Involuntary leakage of small volume of urine & 47 & 41.5 & $<0.001$ & 1.60 \\
\hline & & & High post-void residual volume & 38 & 33.6 & $<0.001$ & 1.52 \\
\hline \multirow[t]{2}{*}{ Functional urinary incontinence } & 83 & 53.2 & Voiding prior to reaching toilet & 67 & 80.7 & $<0.001$ & 5.41 \\
\hline & & & Sensation of need to void & 67 & 80.7 & $<0.001$ & 0.51 \\
\hline
\end{tabular}

continued... 
...continuation

\begin{tabular}{|c|c|c|c|c|c|c|c|}
\hline Variables & $\mathbf{N}$ & $\%$ & & $\mathbf{N}$ & $\%$ & P* & $\mathbf{P R}^{* *}$ \\
\hline \multicolumn{8}{|c|}{ Defining characteristics } \\
\hline & & & $\begin{array}{l}\text { Time between sensation of urge and ability to reach toilet is } \\
\text { too short and involuntary voiding }\end{array}$ & 66 & 79.5 & $<0.001$ & 5.29 \\
\hline & & & Completely empties bladder & 62 & 74.6 & 0.114 & 0.76 \\
\hline & & & Early morning urinary incontinence & 40 & 48.1 & $<0.001$ & 5.41 \\
\hline \multirow[t]{8}{*}{ Reflex urinary incontinence } & 78 & 50.0 & Inability to voluntarily inhibit voiding & 55 & 70.5 & $<0.001$ & 2.33 \\
\hline & & & $\begin{array}{l}\text { Sensation of urgency to void without voluntary inhibition of } \\
\text { bladder contraction }\end{array}$ & 41 & 52.5 & $<0.001$ & 3.00 \\
\hline & & & Absence of urge to void & 28 & 35.8 & 0.079 & 1.33 \\
\hline & & & Sensation of bladder fullness & 22 & 28.2 & 0.002 & 1.72 \\
\hline & & & Inability to voluntarily initiate voiding & 19 & 24.3 & $<0.001$ & 2.19 \\
\hline & & & Absence of voiding sensation & 17 & 21.7 & $<0.001$ & 2.13 \\
\hline & & & Absence of sensation of bladder fullness & 8 & 10.2 & 0.004 & 2.11 \\
\hline & & & Predictable pattern of voiding & 6 & 7.6 & 0.012 & 2.08 \\
\hline \multirow[t]{4}{*}{ Urge urinary incontinence } & 64 & 41.0 & Inability to reach toilet in time to avoid urine loss & 60 & 93.7 & $<0.001$ & 19.41 \\
\hline & & & Urinary urgency & 58 & 90.6 & $<0.001$ & 8.50 \\
\hline & & & Involuntary loss of urine with bladder spasms & 29 & 45.3 & $<0.001$ & 3.48 \\
\hline & & & Involuntary loss of urine with bladder contractions & 29 & 45.3 & $<0.001$ & 3.48 \\
\hline \multirow[t]{6}{*}{ Stress urinary incontinence } & 59 & 37.8 & Involuntary leakage of small volume of urine with sneezing & 38 & 64.4 & $<0.001$ & 5.61 \\
\hline & & & Involuntary leakage of small volume of urine with coughing & 36 & 61.0 & $<0.001$ & 5.21 \\
\hline & & & Involuntary leakage of small volume of urine with laughing & 28 & 47.4 & $<0.001$ & 4.12 \\
\hline & & & $\begin{array}{l}\text { Involuntary leakage of small volume of urine in the absence } \\
\text { of overdistended bladder }\end{array}$ & 19 & 32.2 & $<0.001$ & 3.42 \\
\hline & & & Involuntary leakage of small volume of urine on exertion & 18 & 30.5 & $<0.001$ & 3.36 \\
\hline & & & $\begin{array}{l}\text { Involuntary leakage of small volume of urine in the absence } \\
\text { of detrusor contraction }\end{array}$ & 11 & 18.6 & $<0.001$ & 3.02 \\
\hline
\end{tabular}

* Pearson's Chi-square test; ** Prevalence ratio. Note: $(\mathrm{N}=156)$.

All nursing diagnoses studied were identified in $144 \mathrm{pa}^{-}$ tients, who had at least one diagnosis; similarly, all the defining characteristics were also present. According to Table $1,72.4 \%$ of patients had the diagnosis of Overflow urinary incontinence, the most common defining characteristics found were Overdistended bladder (98.2\%) and Nocturia (86.7\%). All the defining characteristics investigated in relation to the Overflow urinary incontinence nursing diagnosis were statistically associated $(\mathrm{p}<0.05)$. Upon doing the prevalence rate calculation, it was found that the defining characteristics showed a significant risk for the development of diagnostics in the study population.

Functional urinary incontinence nursing diagnosis was present in $53.2 \%$ of the population. The defining characteristics that presented ratio values of significant prevalence for developing Functional urinary incontinence diagnosis were: Voiding prior to reaching toilet $(\mathrm{PR}=5.41)$, Time between sensation of urge and ability to reach toilet is too short and involuntary voiding $(\mathrm{OR}=5.29)$, and Early morning urinary incontinence $(\mathrm{OR}=5.41)$.

The most prevalent defining characteristics for Reflex urinary incontinence nursing diagnosis were Inability to voluntarily initiate voiding (70.5\%) and Sensation of urgency to void without voluntary inhibition of bladder con- traction (52.5\%). The diagnosis that showed a statistically significant association with most of the characteristics investigated and presented the highest prevalence ratio was Sensation of urgency to void without voluntary inhibition of bladder contraction $(\mathrm{PR}=3.00)$.

Also according to the data, $41.0 \%$ of stroke patients were diagnosed with Urge urinary incontinence. The most frequent defining characteristic in this case was Inability to reach toilet in time to avoid urine loss (93.7\%), followed by Urinary urgency (90.6\%). Urge urinary incontinence was significantly associated with all of its defining characteristics, and also all defining characteristics showed a significant risk for the development of Urge urinary incontinence.

Stress urinary incontinence nursing diagnosis was present in $37.8 \%$ of participants. The most prevalent defining characteristics for the diagnosis were: Reports of involuntary leakage of small volume of urine with sneezing (64.4\%), coughing (61.0\%) and laughing (47.4\%). Stress urinary incontinence showed a statistically significant association with all its defining characteristics $(p<0.001)$, and all the defining characteristics showed significant risk for the development of the diagnosis.

By analyzing the associations between urinary incontinence nursing diagnoses, it was found that Stress urinary 
incontinence, Urge urinary incontinence, Functional urinary incontinence and Reflex urinary incontinence are statistically associated with one another $(\mathrm{p}<0.001)$. The diagnosis of Overflow urinary incontinence showed no statistically significant association with the diagnosis of Stress urinary incontinence $(\mathrm{p}=0.785)$ and Reflex urinary incontinence $(\mathrm{p}=0,591)$.

\section{DISCUSSION}

The prevalence of Stress urinary incontinence, Urge urinary incontinence, Functional urinary incontinence, Overflow urinary incontinence and Reflex urinary incontinence nursing diagnoses in the present study vary between $37.8 \%$ and $72.4 \%$ in patients with stroke. An integrative review analyzing eight articles on urinary incontinence found variation in the prevalence of incontinence diagnoses of $22 \%$ to $100 \%{ }^{(13)}$. This variation can be attributed to different search methods, different definitions of urinary incontinence and different clinical characteristics of the samples, as the studies were performed with institutionalized elderly.

Overflow urinary incontinence was the most prevalent diagnosis in patients in the study, even if it is a condition still not very studied by nursing. Overdistended bladder diagnosis had the most prevalent defining characteristic and statistical significance. Corroborating our findings, some authors have found that many older people have urinary leakage when their bladder is full ${ }^{(14)}$. Thus, neurological disorders arising from a stroke can compromise their perception of a filled bladder, leading to involuntary urine loss/voiding.

Another characteristic often found in research with regard to Overflow urinary incontinence diagnosis was Nocturia. This nocturnal disorder can be triggered by various causes, but is probably due to the lowering of the threshold of the stretch receptors in the bladder wall during sleep. The intravesical pressure caused by urine induces an overdistended bladder up to a determined limited. Thus, it generates more afferent impulses that cause the intralaminar thalamus to have the feeling of needing to empty the bladder ${ }^{(15)}$.

Similar findings were observed in a study with adults, showing that nocturia was present in $70.4 \%$ of cases $^{(16)}$, and a study of men with nocturia complaints showed that $12.0 \%$ woke up once during the night to urinate; $21.7 \%$, twice; $28.4 \%$, three times; $26 \%$ four times; and $11.3 \%$, five times ${ }^{(17)}$. In the present study, nocturia was identified as the need to wake up more than once to urinate during the nighttime.

It was found that $41.5 \%$ of participants reported involuntary loss of small volumes of urine. Higher values than ours were found in a study of an incontinent female population, with results showing $74.3 \%$ of women with loss of small volumes of urine. Moreover, $22.5 \%$ had moderate urine loss and only $3.2 \%$ reported urine loss in large quantities ${ }^{(18)}$.

The less frequent defining characteristic in the study participants for the diagnosis of overflow incontinence was High post-void residual volume. Such evidence can be related to the fact that the residual volume after voiding can be accurately determined with a bladder catheter ${ }^{(19)}$. In the present study, the clinical indicator was investigated by the patients' reports of a return to the toilet minutes after urinating, and still losing a lot of urine, conforming to the established definition in the data collection protocol.

Functional urinary incontinence was the second most prevalent diagnostic incontinence. In a study of elderly in a hospital, the prevalence of Functional urinary incontinence was $3 \%$ in clinical medicine and $6 \%$ in the surgical clinic ${ }^{(20)}$. The results of our study showed much lower frequencies to those found in this study, and perhaps this is due to the fact that the mentioned study has methodological differences and does not investigate the phenomenon in detail. In the cited publication, the research had a more comprehensive number of nursing diagnoses listed in NANDA-I, however without detailing how to research each one. In the current study, there was a thorough search of incontinence diagnoses, with a detailed research protocol and a differentiated approach to the participants.

Functional incontinence is designated as urine leakage in cases where there is failure or trouble in getting to the bathroom because of physical, cognitive alterations or environmental barriers, not being caused by a specific comorbidity ${ }^{(13)}$. People with Functional urinary incontinence have the ability to completely empty their bladder, as well as have the urgent feeling to urinate. Often, the high prevalence of this type of incontinence is due to the impossibility or difficulty to reach the bathroom and no fault in the physiology of urination. This condition is present in stroke patients, who often have mobility restriction that prevents them from reaching the bathroom to meet this desire to urinate. Therefore, in this study there was a high number of Sensation of need to void and reports of Voiding prior to reaching the toilet.

It was found that half of the stroke patients developed Reflex urinary incontinence, which is due to the alteration of one or more of the various reflex mechanisms that can lead to bladder emptying action ${ }^{(15)}$. Bladder control is performed by the nervous system, coordinating mechanisms of voluntary and involuntary urination. Voluntary control is done by the cortex of the frontal lobe's side surface and the mesencephalic reticular formation bridge coordinates urination as a whole ${ }^{(15)}$. Thus, during the occurrence of a stroke, when ischemia or bleeding affect these specific areas of the brain, patients can develop this type of incontinence.

The defining characteristic that showed a higher prevalence for the diagnosis of reflex incontinence was Inability to voluntarily inhibit voiding. This reflex is important and contributes to maintaining urinary continence. Elderly or stroke patients may lose control of the urethral sphincter, thereby they are not able to retain urine in the bladder and thus are unable to inhibit emptying/voiding.

Urge urinary incontinence was the fourth most prevalent of the incontinence diagnostics. A study ${ }^{(21)}$ in patients with urological monitoring found $51.7 \%$ of urge incontinence, corroborating the findings of this research. However, in contrast to our findings, the study presents Urge incontinence as the most common type after stroke ${ }^{(22)}$.

The clinical indicator that was more present in the diagnosis of Urge urinary incontinence was Inability to reach toilet in time to avoid urine loss. In contrast to our findings, the investigated study found a lower frequency, verifying smaller 
percentage of urine loss before reaching the bathroom in research with women, for whom the complaint of urinary loss on the way to the bathroom was $53 \%^{(23)}$. Authors have shown that some women leave home only for sites that have a bathroom and always sought to remain close to them, and it shows that the presence of this indicator is a social constraint factor in the lives of people affected by incontinence ${ }^{(24)}$. It is noteworthy that this defining characteristic was the most prevalent for the diagnosis of Urge Incontinence.

Reports of Urinary urgency were quite evident. In an urodynamic study in patients with Alzheimer's disease, detrusor overactivity was found in about $57.6 \%$ of the patients. Moreover, according to the same study, patients with detrusor overactivity have more episodes of urinary urgency ${ }^{(25)}$.

Stress urinary incontinence was the least prevalent diagnosis. Unlike our results, most studies show Stress urinary incontinence as the most prevalent medical condition among urinary incontinence. It is believed that this occurs because studies predominantly adopt the medical classification of urinary incontinence or the classification of the International Continence Society ${ }^{(3)}$ instead of the NANDA-I definition for diagnosis. Other findings verified the higher occurrence of $69.3 \%$ of Stress incontinence in incontinent women attending health community centers ${ }^{(18)}$. Also contrasting our results, a study focused on patients with A1zheimer's disease revealed the diagnosis of Stress incontinence in $25 \%$ of female participants ${ }^{(25)}$. The main causes of involuntary urine leakage were sneezing, coughing and laughing. Corroborating the study data, the prevalence of urinary leakage in women with hip osteoarthritis when coughing or sneezing was $65 \%{ }^{(23)}$.

The results of this investigation demonstrate the importance of research, since it showed a high prevalence of urinary incontinence in stroke patients, presenting different clinical manifestations. Therefore, nurses should not ignore the occurrence of such a phenomenon in their clinical practice and should include parameters to identify human responses to incontinence in their assessment on which to base the choice of specific interventions.

\section{CONCLUSION}

This study has allowed for establishing that the presence of at least one of the nursing diagnoses of Class I (urinary function) is quite significant among stroke patients. At the same time, it allowed to identify the prevalence of actual nursing diagnoses for urinary incontinence and their defining characteristics, as well as the associations of diagnoses among each other and with their defining characteristics.

One of the advantages of the study was the adoption of conceptual and operational definitions of the defining characteristics for the diagnosis under consideration, different from those displayed in NANDA-I. The lack of these definitions can directly interfere in the diagnostic inference process, since recognizing the differences between the denominations of each characteristic is essential. However, even with the construction of definitions, some difficulties were encountered in the collection due to the complexity of measuring some manifestations and relying on information from the participants, without completing exams that could objectify the information.

Despite the difficulties encountered, the study is relevant for identifying the gaps in the literature on the knowledge of the urinary incontinence prevalence in stroke patient survivors in the outpatient treatment phase, drawing attention to the inclusion of detected changes in care planning.

As to the study limitations, we can mention the fact that the study population was only comprised of patients from Fortaleza and in the state of Ceará, and it may not reflect the prevalence of urinary incontinence in stroke patients throughout all regions of Brazil.

We hope that other studies can be implemented, not only with the same types of patients but also including others. We believe that by using an instrument which has already been developed, used and evaluated by nursing judges, the idea is to expand the investigation of the manifestations presented by these patients, in addition to designing nursing interventions focused on health promotion and preventing illnesses/conditions of the subjects.

\section{RESUMO}

Objetivo: Identificar a prevalência dos diagnósticos de enfermagem Incontinência urinária de esforço (IUE), Incontinência urinária de urgência (IUU), Incontinência urinária funcional (IUF), Incontinência urinária por transbordamento (IUT) e Incontinência urinária reflexa (IUR) e suas características definidoras em pacientes com Acidente Vascular Cerebral. Método: Estudo transversal, com 156 pacientes atendidos em ambulatório neurológico. Os dados foram coletados em entrevista e encaminhados a enfermeiros para inferência diagnóstica. Resultados: Dos pacientes avaliados, 92,3\% apresentaram pelo menos um dos diagnósticos do estudo, IUT apresentou maior prevalência (72,4\%), seguido de IUF (53,2\%), IUR (50,0\%), IUU (41,0\%) e IUE (37,8\%). Distensão da bexiga e Relatos de incapacidade de chegar ao banheiro a tempo de evitar perda de urina foram as características definidoras mais prevalentes. Verificou-se associação estatisticamente significante das características definidoras com os diagnósticos estudados. Conclusão: Os cinco diagnósticos de incontinência foram identificados nos pacientes avaliados, apresentando prevalências distintas.

\section{DESCRITORES}

Diagnóstico de Enfermagem; Incontinência Urinária; Acidente Vascular Cerebral.

\section{RESUMEN}

Objetivo: Identificar la prevalencia de los diagnósticos de enfermería Incontinencia urinaria de esfuerzo (IUE), Incontinencia urinaria de urgencia (IUU), Incontinencia urinaria funcional (IUF), Incontinencia urinaria por transborde (IUT) e Incontinencia urinaria refleja (IUR) y sus características definidoras en pacientes con Accidente Vascular Cerebral. Método: Estudio transversal, con 156 pacientes atendidos en ambulatorio neurológico. Los datos fueron recogidos en entrevista y remitidos a enfermeros para inferencia 
diagnóstica. Resultados: De los pacientes evaluados, el 92,3\% presentaron por lo menos uno de los diagnósticos del estudio, IUT presentó mayor prevalencia (72,4\%), seguido de IUF (53,2\%), IUR (50,0\%), IUU (41,0\%) e IUE (37,8\%). Distensión de la vejiga y relatos de incapacidad de llegar al baño a tiempo de evitar pérdida de orina fueron las características definidoras más prevalentes. Se verificó asociación estadísticamente significativa de las características definidoras con los diagnósticos estudiados. Conclusión: Los cinco diagnósticos de incontinencia fueron identificados en los pacientes evaluados, presentando prevalencias distintas.

\section{DESCRIPTORES}

Diagnóstico de Enfermería; Incontinencia Urinaria; Accidente Cerebrovascular.

\section{REFERENCES}

1. NANDA Internacional. Diagnósticos de enfermagem da NANDA 2012/2014: definições e classificação. Porto Alegre: Artmed; 2013.

2. Silva VA, Souza KL, D'Elboux MJ. Urinary incontinence and the criteria of frailness among the elderly outpatients. Rev Esc Enferm USP. 2011;45(3):670-6.

3. Abrams $\mathrm{P}, \mathrm{Cardozo} \mathrm{L}$, Fall M, Griffiths $\mathrm{D}$, Rosier $\mathrm{P}$, Ulmsten U, et al. The standardisation of terminology in lower urinary tract function: report from the Standardisation Sub-Committee of the International Continence Society. Neurourol Urodyn. 2002;21(2):167-78.

4. Berlezi EM, Fiorin AAM, Bilibio PVF, Kirchner RM, Oliveira KR. Estudo da incontinência urinária em mulheres climatéricas usuárias e não usuárias de medicação anti-hipertensiva. Rev Bras Geriatr Gerontol. 2011;14(3):415-23.

5. Cai W, Wang J, Wang L, Wang J, Guo L. Prevalence and risk factors of urinary incontinence for post-stroke inpatients in Southern China. Neurourol Urodyn. 2015;34(3):231-5.

6. Pizzi A, Falsini C, Martini M, Rossetti MA, Verdesca S, Tosto A. Urinary incontinence after ischemic stroke: clinical and urodynamic studie. Neurourol Urodyn. 2014;33(4):420-5.

7. Oliveira LDR, Guirardello EB, Lopes MHBM. The translation and adaptation of the Gaudenz-Fragebogen to the Brazilian culture. Rev Esc Enferm USP. 2012;46(3):565-72.

8. Oliveira ARS, Costa AGS, Moreira RP, Cavalcante TF, Araujo TL. Diagnósticos de enfermagem da classe atividade/exercício em pacientes com acidente vascular cerebral. Rev Enferm UERJ. 2012;20(2):221-8.

9. Cavalcante TF, Araujo TL, Moreira RP, Guedes NG, Lopes MVO, Silva VM. Clinical validation of the nursing diagnosis Risk for Aspiration among patients who experienced a cerebrovascular accident. Rev Latino Am Enfermagem. 2013;21(n.spe):250-8.

10. Morais HCC, Holanda GF, Oliveira ARS, Costa AGS, Ximenes CMB, Araujo TL. Identificação do diagnóstico de enfermagem "risco de quedas em idosos com acidente vascular cerebral". Rev Gaúcha Enferm. 2012;33(2):117-24.

11. Higa R, Lopes MHBM. Avaliação de um sistema especialista em diagnóstico de enfermagem relacionado à eliminação urinária. Rev Bras Enferm. 2008;46(5):565-9.

12. Lopes MVO, Silva VM, Araujo TL. Methods for establishing the accuracy of clinical indicators in predicting nursing diagnoses. Int J Nurs Knowl. 2012;23(3):134-9.

13. Jerez-Roig J, Souza DLB, Lima KC. Incontinência urinária em idosos institucionalizados no Brasil: uma revisão integrativa. Rev Bras Geriatr Gerontol. 2013;16(4):865-79.

14. Silva VA, D'Elboux MJ. Nurses' interventions in the management of urinary incontinence in the elderly: an integrative review. Rev Esc Enferm USP. 2012;46(5):1218-23.

15. Douglas CR. Patofisiologia de sistemas renal. São Paulo: Robe; 2001.

16. Yamanishi T, Fuse M, Yamaguchi C, Uchiyama T, Kamai T, Kurokawa S, et al. Nocturia Quality-of-Life questionnaire is a useful tool to predict nocturia and a risk of falling in Japanese outpatients: a cross-sectional survey. Int J Urol. 2014;21(3):289-93.

17. Fujimura T, Yamada Y, Sugihara T, Azuma T, Suzuki M, Fukuhara H, et al. Nocturia in men is a chaotic condition dominated by nocturnal polyuria. Int J Urol. 2015;22(5):496-501.

18. Xu D, Wang X, Li J, Wang K. The mediating effect of 'bothersome' urinary incontinence on help-seeking intentions among communitydwelling women. J Adv Nurs. 2015;71(2):315-25.

19. Kitta T, Mitsui T, Kanno T, Chiba H, Moriya K, Nonomura K. Postoperative detrusor contractility temporarily decreases in patients undergoing pelvic organ prolapse surgery. Int J Urol. 2015;22(2):201-5.

20. Souza RM, Santana RF, Santo FHE, Almeida JG, Alves LAF. Diagnósticos de enfermagem identificados em idosos hospitalizados: associação com as síndromes geriátricas. Esc Anna Nery. 2010;14(4):732-41.

21. Caruso DJ, Kanagarajah P, Cohen BL, Ayyathurai R, Gomez C, Gousse AE. What is the predictive value of urodynamics to reproduce clinical findings of urinary frequency, urge urinary incontinence, and/or stress urinary incontinence? Int Urogynecol j. 2010;21(10):1205-9.

22. Thomas LH, French B, Burton CR, Sutton C, Forshaw D, Dickinson H, et al. Evaluating a systematic voiding programme for patients with urinary incontinence after stroke in secondary care using soft systems analysis and Normalisation Process Theory: findings from the ICONS case study phase. Int J Nurs Stud. 2014;51(10):1308-20.

23. Tamaki T, Oinuma K, Shiratsuchi H, Akita K, lida S. Hip dysfunction-related urinary incontinence: a prospective analysis of 189 female patients undergoing total hip arthroplasty. Int J Urol. 2014;21(7):729-31.

24. Loureiro LSN, Medeiros ACT, Fernandes MGM, Nóbrega MML. Incontinência urinária em mulheres idosas: determinantes, consequências e diagnósticos de enfermagem. Rev RENE. 2011;12(2):417-23.

25. Lee SH, Cho ST, Na HR, Ko SB, Park MH. Urinary incontinence in patients with Alzheimer's disease: relationship between symptom status and urodynamic diagnoses. Int J Urol. 2014;21(7):683-7. 